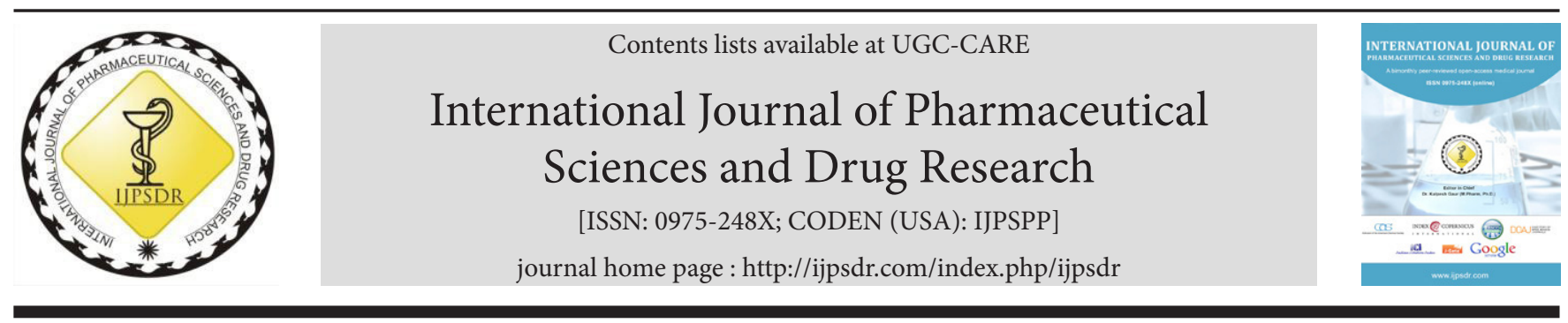

Research Article

\title{
Analyzing the Role of Phytochemicals in targeting Drug Transporter Protein ABCC6 using Molecular Docking and Molecular Dynamics Simulations
}

\author{
Heena Pandya ${ }^{1}$, Chirag N. Patel ${ }^{1}$, Mansi Bhavsar ${ }^{1}$, Pujan N. Pandya ${ }^{1}$, Saumya K. Patel ${ }^{1}$, Rakesh M. Rawal ${ }^{2 *}$ \\ ${ }^{1}$ Department of Botany, Bioinformatics and Climate Change Impacts Management, University School of Sciences, Gujarat University, \\ Ahmedabad-380009, Gujarat, India \\ ${ }^{2}$ Department of Life Sciences, University School of Sciences, Gujarat University, Ahmedabad-380009, Gujarat, India
}

\begin{tabular}{l} 
A R T I C L E I N F O \\
\hline Article history: \\
Received: 29 February, 2020 \\
Revised: 22 April, 2020 \\
Accepted: 28 April, 2020 \\
Published: 30 May, 2020 \\
Keywords: \\
ADMET, Drug resistance, \\
Molecular docking, \\
Molecular dynamics simulations, \\
Phytochemicals, \\
Triple-negative breast cancer \\
(TNBC). \\
D0I: \\
10.25004/IJPSDR.2020.120310
\end{tabular}

\section{IN T RODUCTION}

Breast cancer $(\mathrm{BC})$ is one of the most common malignancies amongst women across the globe. Of all molecular subtypes of breast cancer, TNBC is the mostaggressive subtypes with increased rates of recurrence and metastasis. It accounts for 10 to $15 \%$ of all breast cancer types with high histologic grade. ${ }^{[1]}$ This subtype of $B C$ is characterized by a lack of hormonal receptor expression-estrogen (ER) negative, progesterone (PR) negative, and absent or reduced levels of HER2 protein. TNBC shows a strong correlation with $\mathrm{BC}$ gene (BRCA) 1/2 mutations and is commonly found in young and obese women. There are limited treatment options for TNBC patients. Hormonal and targeted therapies do not work for TNBC patients, as TNBC lacks hormone receptors and reduced HER2 levels. ${ }^{[2]}$ Lack of hormonal receptors makes treatment of TNBC even more challenging. Chemotherapy and adjuvant chemotherapy are limited treatment options for TNBC patients. ${ }^{[1]}$ Drug resistance is another major obstacle in the treatment of TNBC. Patients receiving chemotherapy often face drug resistance to a broad spectrum of chemotherapeutic agents. Of several factors that cause drug resistance in cancer, ATP-binding cassette (ABC) drug transporters are the major causative factor inducing drug resistance. ${ }^{[3]}$

\footnotetext{
${ }^{*}$ Corresponding Author: Rakesh M. Rawal

Address: Department of Life Sciences, University School of Sciences, Gujarat University, Ahmedabad-380009, Gujarat, India

Email $₫$ : rakeshmrawal@gmail.com

Relevant conflicts of interest/financial disclosures: The authors declare that the research was conducted in the absence of any commercial or financial relationships that could be construed as a potential conflict of interest.

Copyright (C) 2020 Heena Pandya et al. This is an open access article distributed under the terms of the Creative Commons Attribution- NonCommercialShareAlike 4.0 International License which allows others to remix, tweak, and build upon the work non-commercially, as long as the author is credited and the new creations are licensed under the identical terms.
} 
ATP-binding cassette $(\mathrm{ABC})$ transporter superfamily members are involved in the transport of molecules across the cell membrane. ${ }^{[4]}$ The structure of ABC transporters consists of two nucleotide-binding domains (NBD) and two transmembrane domains (TMD). ${ }^{[5]}$ On the basis of sequence similarity and structure, the transporter family has been divided into seven subfamilies, designated as $\mathrm{ABC} A-\mathrm{G}^{[6]} \mathrm{ABCC6}$, also known as multi-resistance protein (MRP) 6 belongs to $\mathrm{ABC}$ gene subfamily $\mathrm{C}$ and is encoded by the ABCC6 gene. ABCC6 is efflux transporter and effectively pumps NEM-GS (glutathione conjugate of $\mathrm{N}$-ethlmaleimide and LTC4 (leukotriene C4). ${ }^{[7-9]}$ Dysregulation of ABCC6 is observed in TNBC..$^{[10-13]}$ Studies show that MRP 6 is capable of inducing drug resistance in cancer for etoposide, doxorubicin, daunorubicin, cisplatin, and actinomycin D. ${ }^{[14,15]}$

For hundreds of years, humans have used herbs and plants for the treatment of several diseases. ${ }^{[16-19]}$ Enough emphasis has been made on the relevance of phytochemicals (biologically active plant chemicals) in cancer prevention. Plants have been used as an alternative to chemotherapeutic drugs in cancer treatment, and more than 3,000 plants have been reported to exhibit anticancer properties. ${ }^{[20]}$ Phytochemicals have shown cancer preventive properties, ability to restore sensitivity in resistant cancer cells, ${ }^{[21,22]}$ and increase the efficiency of chemotherapeutic drugs. ${ }^{[23]}$ Inhibitory action on NF- $\kappa \mathrm{B}$, a key player in tumorigenesis, has been observed by resveratrol, limonene, gingerol, genistein, apigenenin, and many others. ${ }^{[24]}$

Bioinformatics tools, like molecular docking, enable understanding of ligand interaction with small molecules, like substrate or regulators. ${ }^{[25]}$ Molecular docking has gained immense importance in drug designing and discovery as they are fast, reliable, and economic alternative to the experimental approach. Molecular docking is used to find binding poses and binding affinity prediction. These predictions further suggest use of candidates as active compounds. ${ }^{[26]}$ Molecular dynamics simulations study was developed in the late 1970s and has gained immense importance in studying atoms and molecules of biological importance. It enables the study of entire protein complexes in solvents, in proteins embedded in membranes or in nucleosomes or ribosomes complexes. Molecular dynamics study is a widely used simulation tool that allows understanding protein-ligand interactions at increased flexibility more effectively than molecular docking. ${ }^{[27]}$ Molecular dynamics simulation allows evaluation of protein structures in equilibrium state. The binding ability and stability of protein-ligand complexes were evaluated using molecular dynamics simulations, ${ }^{[28,29]}$ while molecular docking uses rigid structures obtained from protein data bank (PDB), molecular dynamics (MD) simulations work in more relevant dynamics. ${ }^{[30]}$

Resistant cancers have become a major problem in treating patients. In this study, 1,574 natural compounds were docked with ABCC6 protein to evaluate the binding stability of protein-ligand complex, and molecular dynamics simulations were performed of ABCC 6 protein and docked phytochemical subtrifloralactone G. ADMET properties were also checked for ligand subtrifloralactone $\mathrm{G}$.

\section{Materials AND Methods}

\section{ABCC6 Protein Preparation}

The protein structure of ABCC6 was downloaded from Research Collaboratory for Structural Bioinformatics (RCSB) PDB (Fig. 1). PDB ID of ABCC6 protein is 6BZR, which is inbound with ADP ligand (adenosine-5'-diphosphate) $\left(\mathrm{C}_{10} \mathrm{H}_{15} \mathrm{~N}_{5} \mathrm{O}_{10} \mathrm{P}_{2}\right)$ and citric acid $\left(\mathrm{C}_{6} \mathrm{H}_{8} \mathrm{O}_{7}\right)$. It is a membrane transport protein in Homo sapiens. It has two chains, A and B, with a 251 sequence length. The crystal structure of this protein is obtained through X-ray diffraction with resolution $2.79 \AA$. Water molecules were removed, and the energy minimization step was performed with the help of the standard steepest descent method in "yet another scientific artificial reality application" (YASARA). ${ }^{[31]}$

\section{Preparation of Natural Compounds}

In this study, the ligands were derived from naturally occurring plant-based anti-cancer compound activity target (NPACT) database (http://crdd.osdd.net/raghava/ npact/). This database has approximately 1,500 natural compounds with known anti-cancer activities, and these compounds were compiled into a single dataset for docking purposes. For further use, ligands were cleaned, and hydrogens were added using the Marvin sketch tool. ${ }^{[32]}$

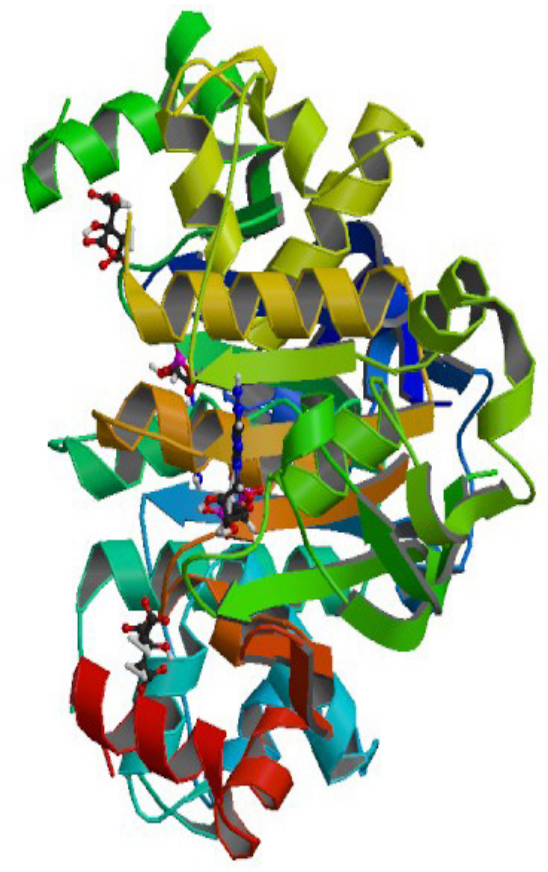

Fig. 1: ABCC6 protein structure downloaded from PDB (PDB ID: 6BZR) 


\section{Molecular Docking}

It is an important tool in structural biology and assists in computational drug designing by presenting the interactions between two molecules and finds most feasible orientation that forms a reliable complex with minimum energy. The main objective of molecular docking is prediction of protein-ligand complex, wherein ligand binds to the cavity of protein. These cavities are called active sites as these sites become functionally active when acted by external molecules. ${ }^{[33]}$ Docking is a crucial step to choose potential hits in virtual screening. It allows interaction between different atoms and molecules for a fixed period of time. ${ }^{[34]}$ YASARA software was used to investigate the detailed interactions between hits and drug transporter proteins ABCC6. For molecular docking, YASARA uses AutoDock Vina 4.2 algorithm and AMBER03 force field. Removal of water molecules, small ions, and energy minimization was performed in YASARA. A profile was generated of all the hits and proteins. The proteinligand interactions were further visualized in Discovery Studio. The free binding energy $\Delta G_{\text {bind }}$ was given by the following equation:

$\Delta G=\Delta G_{\mathrm{vdW}}+\Delta G_{\text {Hbond }}+\Delta G_{\text {elec }}+\Delta G_{\text {tor }}+\Delta G_{\text {desolv }}$ where, $\Delta G_{\mathrm{vdW}}=$ van der Waals term for docking energy; $\Delta G_{\mathrm{Hbond}}=\mathrm{H}$ bonding term for docking energy; $\Delta G_{\text {elec }}=$ electrostatic term for docking energy; $\Delta G_{\text {tor }}=$ torsional free energy term for ligand when the ligand transits from unbounded to bounded state; $\Delta G_{\text {desolv }}=$ desolvation term for docking energy.

The results of molecular docking are dependent on two factors: optimization search method, which detects docking complexes with minimum binding energies, and scoring function is used as benchmark to evaluate results obtained after docking. ${ }^{[35]}$

\section{Molecular Dynamics Simulations}

Molecular dynamics simulations allow understanding of binding stability of desired ligands to the proteins. A molecular dynamics simulation study was undertaken by using YASARA with AMBER03 force field for docked complex. Energy minimization was performed for proteinligand complexes to remove unfavorable atoms. Steepest descent minimization was used, and simulation was continued at $10 \mathrm{~ns}$. The molecular dynamics simulation was carried out within simulation box at following conditions: temperature $298 \mathrm{~K}$, pressure 1 bar, coulomb electrostatics at cut-off 7.86, $0.9 \% \mathrm{NaCl}$, solvent density 0.997, pH 7.0, 1-fs time steps, periodic boundaries, and all atoms mobile. ${ }^{[34]}$ The molecular complexes were stimulated at $10 \mathrm{~ns}$ with frame capture at every $2.5 \mathrm{~ns}(0$, $2.5,5,7.5$, and $10 \mathrm{~ns}$ ). Different trajectories were analyzed through several quantities, including root mean squared deviation (RMSD). ${ }^{[35]}$

\section{ADMET Analysis}

To check different ADMET properties, admetSAR (http:// www.admetexp.org) and Molinspiration tool (https:// www.molinspiration.com/) was used.

\section{RESULTS AND DISCUSSION}

\section{Molecular Docking}

In drug designing, molecular docking is the first approach to check feasibility of any biochemical reaction before carrying out experimental approach. This approach allows prediction of several different binding sites in target allowing development and selection of efficient and potent drug candidates. It also allows in silico evaluation of large databases to search for potent drug candidates. ${ }^{[36]}$

For ABCC6, the three bestligands are subtrifloralactone, helioxanthin, and 5-beta-spirostan-3-beta-ol 3-0-beta-Dglucopyranosyl-(1-2)-beta-D-glucopyranoside (Table 1). Subtrifloralactone $\mathrm{G}$ showed highest binding energy $(9.053 \mathrm{kcal} / \mathrm{mol})$. Positive YASARA score indicates stronger, stable, and efficient binding. Contacting residue receptors, hydrogen bond interactions, pi-sigma bond, alkyl bond, and pi-alkyl bond were noted. Fig. 2 shows docked results of ABCC6 protein and subtrifloralactone $G$ in 3D and 2D format with different interactions at specified distances.

Fig. 2 shows 3D and 2D pose of ABCC 6 proteinsubtrifloralactone $\mathrm{G}$ ligand complex. The active compound, subtrifloralactone $\mathrm{G}$ showed hydrogen bond interactions with residues Ser-1306, Gly-1304, Ser-1307, and Lys1305, van der Waals interactions with residues Tyr-1274, Thr-1301, Ile-1456, Val-1282, Ala-1303, Gly-1475, and Leu1280, alkyl bonds with residues Ala-1281, Pro-1279, and pi-alkyl bonds with residues His-1458. Forces between

Table 1: Top three molecular docking results of phytochemicals with ABCC6

\begin{tabular}{lll}
\hline Ligand name & $\begin{array}{l}\text { Binding energy } \\
\text { (kcal/mol) }\end{array}$ & Contacting residue receptors \\
\hline Subtrifloralactone G & 9.053 & $\begin{array}{l}\text { Tyr 1274, Leu 1278, Pro 1279, Leu 1280 Ala 1281, Val 1282, Arg 1300, } \\
\text { Thr 1301, Gly 1302, Ala 1303, Gly 1304, Lys 1305, Ser 1306, Ser 1307, } \\
\text { Ile 1456, His 1458, Lys 1474, Gly A 1475 }\end{array}$ \\
Helioxanthin & & $\begin{array}{l}\text { Tyr 1274, Leu 1278, Pro 1279, Leu 1280, Ala 1281, Thr 1301, Gly 1302, } \\
\text { Ala 1303, Gly 1304, Lys 1305, Ser 1306, Ser 1307 }\end{array}$ \\
$\begin{array}{l}\text { 5-beta-spirostan-3-beta-ol 3-0-beta- } \\
\begin{array}{l}\text { D-glucopyranosyl-(1-2)-beta-D- } \\
\text { glucopyranoside }\end{array}\end{array}$ & 9.03 & $\begin{array}{l}\text { Tyr 1274, Leu 1278, Pro 1279, Leu 1280, Ala 1281, Arg 1300, Thr 1301, } \\
\text { Gly 1302, Ala 1303, Gly 1304, Lys 1305, Ser 1306, Ser 1307, Pro 1346, }\end{array}$ \\
\hline
\end{tabular}




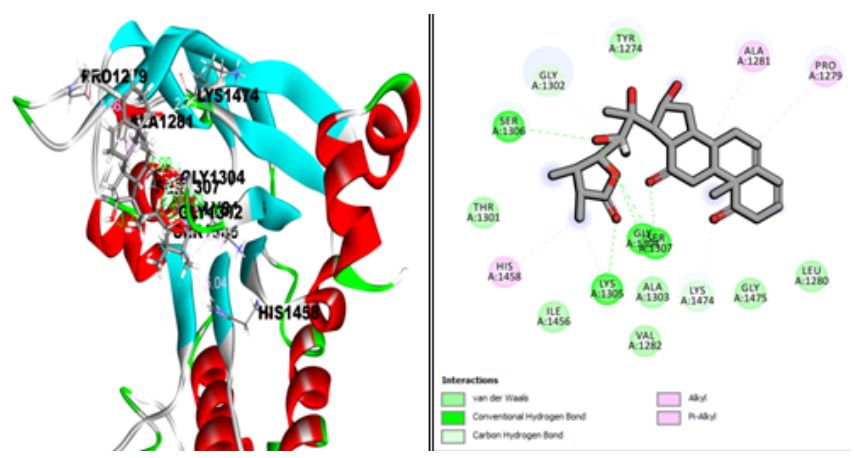

Fig. 2: 3D and 2D pose of ABCC6 and subtrifloralactone $G$

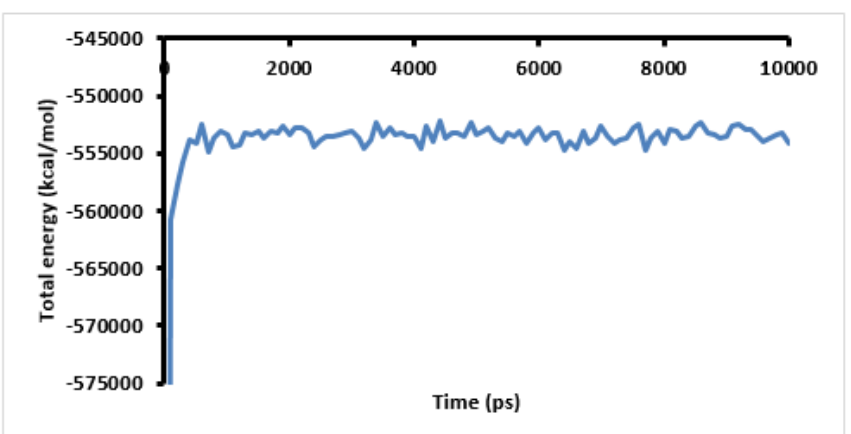

Fig. 3: Time (ps) vs. energy (kJ/mol) plot of ABCC6 proteinsubtrifloralactone $\mathrm{G}$ ligand complex

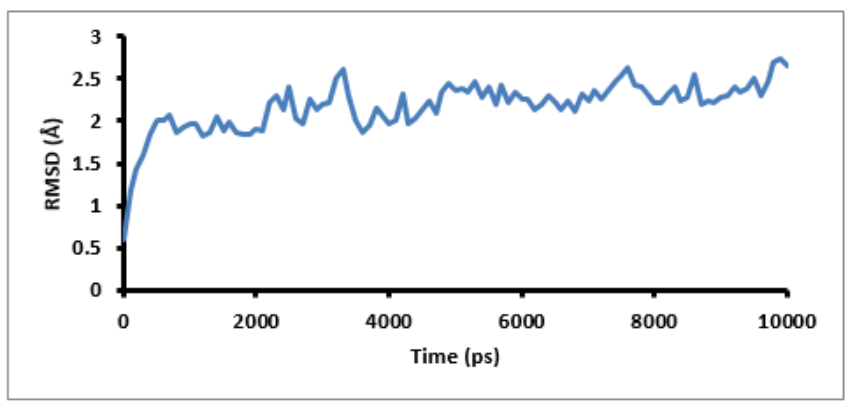

Fig. 4: Time (ps) vs. RMSD $(\AA)$ of ABCC6 protein-subtrifloralactone $\mathrm{G}$ ligand complex

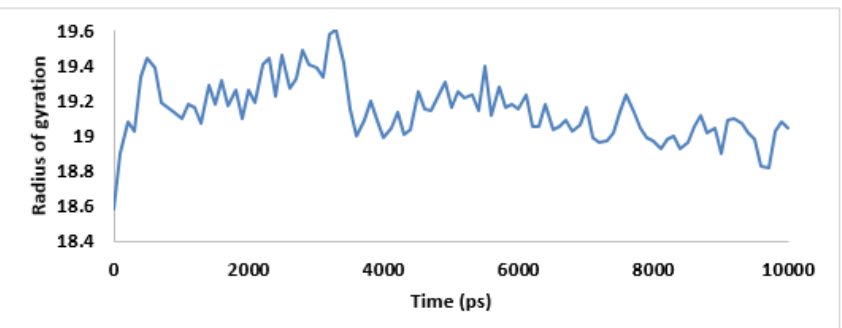

Fig. 5: Time (ps) vs. radius of gyration plot of ABCC6 proteinsubtrifloralactone G ligand complex

molecules create interactions between the particles. There are four main types of interactions, viz., electrostatic forces due to charges within the compound, electrodynamics forces, or van der Waals forces, steric forces that are generated due to proximity of different molecules and solvent related forces, like hydrophilic (hydrogen bonds) and hydrophobic interactions. ${ }^{[33]}$

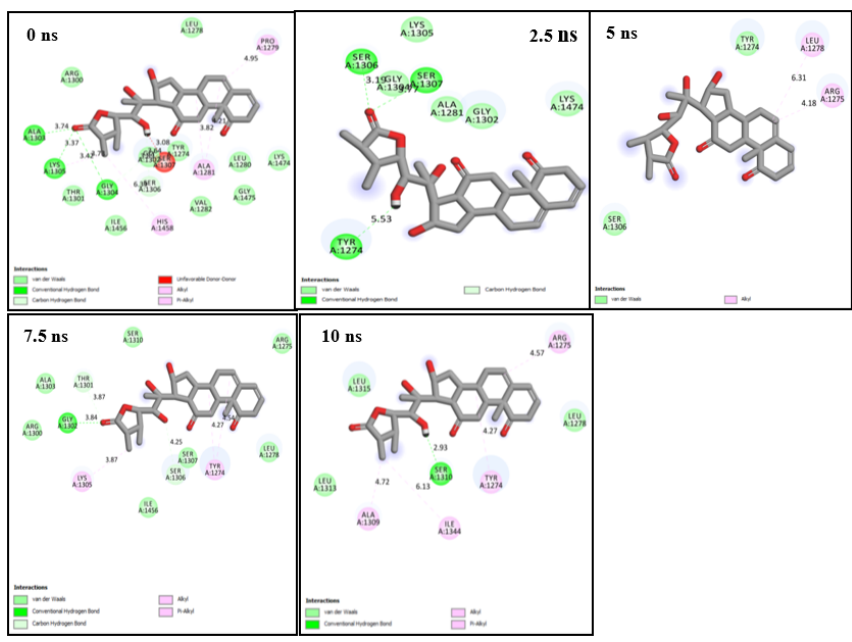

Fig. 6: Conformational changes in protein-ligand complex observed after every $2.5 \mathrm{~ns}$ of the molecular dynamics simulation (10 ns)

Table 2: ADMET properties of compound subtrifloralactone $\mathrm{G}$

\begin{tabular}{llc}
\hline ADMET properties & \multicolumn{2}{l}{ Subtrifloralactone $G$} \\
\hline Blood-brain barrier penetration & + & 0.81 \\
Human intestinal absorption & + & 0.96 \\
CYP2D6 inhibitor & - & 0.94 \\
Caco-2 cell permeability & - & 0.79 \\
Carcinogenicity & - & 0.97 \\
Human oral bioavailability & - & 0.68 \\
\hline
\end{tabular}

\begin{tabular}{ll}
\hline \multicolumn{2}{c}{ Table 3: Lipinski's rule of five } \\
\hline Molecular weight & 472.58 \\
\hline AlogP & 1.98 \\
H-bond acceptor & 7 \\
H-bond donor & 3 \\
Rotatable bonds & 3 \\
\hline
\end{tabular}

The protein-ligand complex ABCC6 and subtrifloralactone $\mathrm{G}$ was further subjected to molecular dynamics simulations. Certain conditions were kept constant during simulations, like number of atoms, pressure, temperature, $\mathrm{pH}$, and density. Fig. 3 shows time (in ps) vs. energy $(\mathrm{kJ} / \mathrm{mol})$ plot that depicts fluctuations of the complexes. Time (in ps) vs. RMSD plot (Fig. 4) shows stability of docked protein-ligand complex. Fig. 5 shows time (in ps) vs. radius of gyration plot, which shows spatial packing of amino acid residues, which shows protein stability. Higher value of radius of gyration indicates less compact structure. Further, the docked complexes were visualized in Discovery Studio 3 to display various interactions involved in the protein-ligand docking. Fig. 6 shows conformational changes in the protein-ligand complex when simulated at time period of $10 \mathrm{~ns}$.

Multi-drug resistance proteins (MRP) are membrane glycoproteins that are ATP-dependent and facilitate the export of drugs from cells. ${ }^{[37]}$ ABCC6 is an efflux drug transporter with a known role in inducing resistance to 
Role of Phytochemicals in targeting Drug Transporter Protein ABCC6

Table 4: Drug-likeness of subtrifloralactone G ligand

\begin{tabular}{lllllllll}
\hline miLogP & TPSA & MW & natoms & nON & nOHNH & nviolations & nrotb & volume \\
\hline 0.94 & 121.13 & 472.58 & 34 & 7 & 3 & 0 & 3 & 437.98 \\
\hline
\end{tabular}

drugs, like etoposide, doxorubicin, daunorubicin, cisplatin, and actinomycin D. ${ }^{[38]}$

\section{ADMET Analysis}

ADMET analysis allows computational analysis of absorption, distribution, metabolism, excretion, and toxicity properties of drug candidate. In this study, we performed ADMET analysis of subtrifloralactone $\mathrm{G}$ compound to check whether it can be used as drug candidate or not. Several analyses like blood-brain barrier penetration, human intestinal absorption, CYP2D6 inhibitor, Caco-2 cell permeability, carcinogenicity, and biodegradation were calculated. The cytochrome P450 family plays a critical role in drug metabolism and excretion through liver. CYP1A2, CYP2A6, CYP2C9, CYP2C19, CYP2D6, CYP2E1, and CYP3A4 are the most important isoforms. Dysregulation of these isoforms may lead to decreased drug metabolism. BBB is a highly selective membrane that prevents blood components from crossing the extracellular fluid in brain. Health impact assessment (HIA), Caco-2 cell permeability, and bioavailability are also important parameters that are considered for potential drug identification. ${ }^{[39]}$ Table 2 shows blood-brain barrier penetration, human intestinal absorption, CYP2D6 inhibitor, Caco-2 cell permeability, carcinogenicity, and biodegradation. Subtrifloralactone $\mathrm{G}$ shows BBB penetration and HIA, but fails to show Caco-2 permeability. The compound also exhibits negative human oral bioavailability. The major drawback of natural compounds is reduced bioavailability. However, this can be solved by chemically modifying the structure or by using nanoparticle delivery of drugs in the body. ${ }^{[40]}$

Lipinski's rule of five states that a drug candidate should fulfill certain conditions to be used in humansoctanol-water partition coefficient $(\log \mathrm{P})$ should be $<5$, molecular weight $\leq 500 \mathrm{kDa}$, number of $\mathrm{H}$-bond donors should be $\leq 5$; number of $\mathrm{H}$-bond receptors should be $\leq 10 .^{[39]}$ Another rule was included: the number of rotatable bonds should be $<10$ (Table 3).

\section{Molinspiration Analysis}

Molecular weight plays a key role in determining the therapeutic efficiency of the drug. Bulkier molecules cannot be easily transported, diffused, and absorbed when compared to lighter molecules. The molecular weight of subtrifloralactone $\mathrm{G}$ is 472.58 , which is $<500$. Oral bioavailability of drug molecules was characterized by lipophilicity (log P value) and topological polar surface area (TPSA) values. Log $P$ value for subtrifloralactone $G$ is 0.94 . This value is within the acceptable limit for drug permeability. Table 4 shows that subtrifloralactone $G$ ligand showed no violations of drug-likeness conditions.
The compound subtrifloralactone $G$ is derived from D. subtriflora (Solanaceae family), a plant native to Peru. ${ }^{[41]}$ Subtrifloralactone is a withanolide that are found exclusively in Solanaceae family. ${ }^{[42]}$ Withanolides have shown potential in anti-tumor, anti-stress, anti-microbial, and anti-inflammatory activities. These withanolides have exhibited the potential to function as chemopreventive agents. 10 norwithanolides (a subclass of withanolides), subtrifloralactone A-J are isolated from D. subtriflora. ${ }^{[41]}$ The helioxanthin is extracted from Taiwania cryptomerioides plant. This phytochemical exhibits a broad spectrum of activities. A study by YuehMin Lin showed anti-cancer activity of helioxanthin in oral squamous cell carcinoma. ${ }^{[43]}$

Drug resistance poses as one of the major obstacles in cancer treatment management. ABC transporter family plays an important factor in inducing resistance to drugs in cancer treatment. Up regulation of ABCC6, an efflux drug transporter is found in diverse cancer types. ${ }^{\text {[44-46] }}$ Molecular docking was used to investigate ABCC6 proteinphytochemicals ligand affinity. ABCC6 protein has been observed to be interacting with subtrifloralactone $G$, helioxanthin, and 5-beta-spirostan-3-beta-ol 3-0-betaD-glucopyranosyl-(1-2)-beta-D-glucopyranoside with binding energies 9.053, 9.03, and $8.914 \mathrm{kcal} / \mathrm{mol}$, respectively. Molecular dynamics simulations showed that subtrifloralactone $\mathrm{G}$ shows stable configuration and has potential to be used as an anti-cancer agent. Molecular dynamics simulations results support the hypothesis that phytochemicals are reliable ligands that can be used as anti-cancer therapeutic agents. These results could be further used for designing phytochemicals derived drugs for resistant cancer types. ADMET analysis shows that subtrifloralactone $\mathrm{G}$ can be used as potential therapeutic candidate in targeting ABCC6 protein; however, further analysis is required to validate these results.

\section{ACKNOWLEDGEMENT}

This work was financially supported by the Financial Assistance Programme-Gujarat State Biotechnology Mission, Gujarat, India [grant number GSBTM/FAP/1443], and Department of Science and Technology [grant number GSBTM/MD/JDR/1409/2017-18].

\section{REFERENCES}

1. Lebert JM, Lester R, Powell E, Seal M, McCarthy J. Advances in the systemic treatment of triple-negative breast cancer. Current Oncology. 2018 Jun;25(Suppl 1):S142.

2. Foulkes WD, Smith IE, Reis-Filho JS. Triple-negative breast cancer. New England Journal of Medicine. 2010 Nov 11;363(20):1938-1948.

3. O'Driscoll L, Clynes M. Molecular markers of multiple drug resistance in breast cancer. Chemotherapy. 2006;52(3):125-129. 
4. Mansoori B, Mohammadi A, Davudian S, Shirjang S, Baradaran B. The different mechanisms of cancer drug resistance: a brief review. Advanced pharmaceutical bulletin. 2017 Sep;7(3):339.

5. Begicevic RR, Falasca M. ABC transporters in cancer stem cells: beyond chemoresistance. International Journal of Molecular Sciences. 2017 Nov;18(11):2362.

6. Sun YL, Patel A, Kumar P, Chen ZS. Role of ABC transporters in cancer chemotherapy. Chinese Journal of Cancer. 2012 Feb;31(2): 51.

7. Iliás A, Urbán Z, Seidl TL, Le Saux O, Sinkó E, Boyd CD, et al. Loss of ATP-dependent transport activity in pseudoxanthoma elasticumassociated mutants of human ABCC6 (MRP6). Journal of Biological Chemistry. 2002 May 10;277(19):16860-16867.

8. Belinsky MG, Chen ZS, Shchaveleva I, Zeng H, Kruh GD. Characterization of the drug resistance and transport properties of multidrug resistance protein 6 (MRP6, ABCC6). Cancer Research. 2002 Nov 1;62(21):6172-6177.

9. Beck K, Hayashi K, Hayashi M, Boyd CD. Analysis of ABCC6 (MRP6) in normal human tissues. Histochemistry and Cell Biology. 2005 Jun 1;123(4-5):517-528.

10. Stewart PA, Luks J, Roycik MD, Sang QX, Zhang J. Differentially expressed transcripts and dysregulated signaling pathways and networks in African American breast cancer. PloS one. 2013; $8(12)$.

11. Soleymani Abyaneh H, Gupta N, Radziwon-Balicka A, Jurasz P, Seubert J, Lai R, et al. STAT3 but not HIF- $1 \alpha$ is important in mediating Hypoxia-Induced chemoresistance in MDA-MB-231, a triple negative breast cancer cell line. Cancers. 2017 Oct;9(10):137.

12. Zhou Y, Wang Y, Zhou W, Chen T, Wu Q, Chutturghoon VK, et al. YAP promotes multi-drug resistance and inhibits autophagy-related cell death in hepatocellular carcinoma via the RAC1-ROS-mTOR pathway. Cancer Cell International. 2019 Dec 1;19(1):179.

13. Manna A, Banerjee S, Khan P, Bhattacharya A, Das T. Contribution of nuclear events in generation and maintenance of cancer stem cells: revisiting chemo-resistance. The Nucleus. 2017 Aug 1;60(2): 121-135.

14. Belinsky MG, Chen ZS, Shchaveleva I, Zeng H, Kruh GD. Characterization of the drug resistance and transport properties of multidrug resistance protein 6 (MRP6, ABCC6). Cancer Research. 2002 Nov 1;62(21):6172-6177.

15. Kruh GD, Belinsky MG. The MRP family of drug efflux pumps. Oncogene. 2003 Oct;22(47):7537-7552.

16. Seca A, Pinto D. Plant secondary metabolites as anti-cancer agents: successes in clinical trials and therapeutic application. International Journal of Molecular Sciences. 2018 Jan 16;19(1):263.

17. Liu RH. Potential synergy of phytochemicals in cancer prevention: mechanism of action. The Journal of nutrition. 2004 Dec 1; 134(12):3479S-85S.

18. Johnson IT, Williamson G, Musk SR. Anticarcinogenic factors in plant foods: a new class of nutrients? Nutrition Research Reviews. 1994 Jan;7(1):175-204.

19. Johnson IT. Mechanisms and anticarcinogenic effects of diet-related apoptosis in the intestinal mucosa. Nutrition Research Reviews. 2001 Dec;14(2):229-256.

20. Aggarwal BB, Kunnumakkara AB, Harikumar KB, Tharakan ST, Sung $B$, Anand P. Potential of spice-derived phytochemicals for cancer prevention. Planta Medica. 2008 0ct;74(13):1560-1569.

21. Zeng C, Fan D, Xu Y, Li X, Yuan J, Yang Q, et al. Curcumol enhances the sensitivity of doxorubicin in triple-negative breast cancer via regulating the miR-181b-2-3p-ABCC 3 axis. Biochemical Pharmacology. 2020 Jan 10:113795.

22. Tan KW, Li Y, Paxton JW, Birch NP, Scheepens A. Identification of novel dietary phytochemicals inhibiting the efflux transporter breast cancer resistance protein (BCRP/ABCG2). Food Chemistry. 2013 Jun 15;138(4):2267-2274.

23. Nabekura T, Yamaki T, Ueno K, KitagawaS. Inhibition of P-glycoprotein and multidrug resistance protein 1 by dietary phytochemicals. Cancer Chemotherapy and Pharmacology. 2008 Oct 1;62(5): 867-873.
24. Johnson IT. Phytochemicals and cancer. Proceedings of the Nutrition Society. 2007 May;66(2):207-215.

25. Koshland DE. Application of a theory of enzyme specificity to protein synthesis. Proceedings of the National Academy of Sciences. 1958 Feb 1;44(2):98-104.

26. Fu Y, Zhao J, Chen Z. Insights into the molecular mechanisms of protein-ligand interactions by molecular docking and molecular dynamics simulation: a case of oligopeptide binding protein. Computational and mathematical methods in medicine. 2018.

27. Meng XY, Zhang HX, Mezei M, Cui M. Molecular docking: a powerful approach for structure-based drug discovery. Current computeraided drug design. 2011 Jun 1;7(2):146-157.

28. Seniya C, Khan GJ, Uchadia K. Identification of potential herbal inhibitor of acetylcholinesterase associated Alzheimer's disorders using molecular docking and molecular dynamics simulation. Biochemistry research international. 2014;2014.

29. Parmar R, Patel CN, Highland H, Desai K, George LB. Pesticide Target Protein and Phytochemical Interactions-A Computational Study Mitigating Mosquito-Vectors. InYoung Scientists' Conference, India International Science Festival 2015.

30. Hospital A, Goñi JR, Orozco M, Gelpí JL. Molecular dynamics simulations: advances and applications. Advances and applications in bioinformatics and chemistry: AABC. 2015;8:37.

31. Patel CN, Georrge JJ, Modi KM, Narechania MB, Patel DP, Gonzalez FJ, et al. Pharmacophore-based virtual screening of catechol-omethyltransferase (COMT) inhibitors to combat Alzheimer's disease. Journal of Biomolecular Structure and Dynamics. 2018 Nov 18;36(15):3938-3957.

32. Trott 0, Olson AJ. Software news and update AutoDock Vina: improving the speed and accuracy of docking with a new scoring function, and multithreading. J Comput Chem. 2010;31:455-461.

33. Patel CN, Narechania MB. Targeting epidermal growth factor receptors inhibition in non-small-cell lung cancer: a computational approach. Molecular Simulation. 2018 Nov 22;44(17):1478-1488.

34. Pandya PN, Mankad AU, Rawal RM, Prasanth KS. Screening of diverse phytochemicals with Aurora Kinase C protein: An In silico approach. Journal of Drug Delivery and Therapeutics. 2019 Feb 15; 9(1-s):67-74.

35. Pandya PN, Kumar SP, Bhadresha K, Patel CN, Patel SK, Rawal RM, et al. Identification of promising compounds from curry tree with cyclooxygenase inhibitory potential using a combination of machine learning, molecular docking, dynamics simulations and binding free energy calculations. Molecular Simulation. 2020 May 16:1-1.

36. Dar AM, Mir S. Molecular docking: approaches, types, applications and basic challenges. J Anal Bioanal Tech. 2017 Apr;8(2):1-3.

37. Nies AT, Jedlitschky G, König J, Herold-Mende C, Steiner HH, Schmitt HP, Keppler D. Expression and immunolocalization of the multidrug resistance proteins, MRP1-MRP6 (ABCC1-ABCC6), in human brain. Neuroscience. 2004 Jan 1;129(2):349-360.

38. Lage H, Dietel M. Effect of the breast-cancer resistance protein on atypical multidrug resistance. The Lancet Oncology. 2000 Nov 1; 1(3):169-175.

39. Alhazmi MI. Molecular docking of selected phytocompounds with H1N1 Proteins. Bioinformation. 2015;11(4):196.

40. Xie J, Yang Z, Zhou C, Zhu J, Lee RJ, Teng L. Nanotechnology for the delivery of phytochemicals in cancer therapy. Biotechnology advances. 2016 Jul 1;34(4):343-353.

41. Su BN, Park EJ, Nikolic D, Santarsiero BD, Mesecar AD, Vigo JS, et al. Activity-guided isolation of novel norwithanolides from deprea s ubtriflora with potential cancer chemopreventive activity. The Journal of Organic Chemistry. 2003 Mar 21;68(6):2350-2361.

42. Casero CN, Oberti JC, Orozco CI, Cárdenas A, Brito I, Barboza GE, etal. Withanolides from three species of the genus Deprea (Solanaceae). Chemotaxonomical considerations. Phytochemistry. 2015 Feb 1; 110:83-90.

43. Lin YM, Kuo WW, Velmurugan BK, Hsien HH, Hsieh YL, Hsu HH, et al. Helioxanthin suppresses the cross-talk of COX-2/PGE2 and EGFR/ ERK pathway to inhibit Arecoline-induced Oral Cancer Cell (T28) proliferation and blocks tumor growth in xenografted nude mice. 
Environmental toxicology. 2016 Dec;31(12):2045-2056.

44. Cerovska E, Elsnerova K, Vaclavikova R, Soucek P. The role of membrane transporters in ovarian cancer chemoresistance and prognosis. Expert opinion on drug metabolism \& toxicology. 2017 Jul 3;13(7):741-753.

45. Scheffer GL, Hu X, Pijnenborg AC, Wijnholds J, Bergen AA, Scheper RJ.
MRP6 (ABCC6) detection in normal human tissues and tumors. Laboratory investigation. 2002 Apr;82(4):515-518.

46. Moitra K, Im K, Limpert K, Borsa A, Sawitzke J, Robey R, et al. Differential gene and microRNA expression between etoposide resistant and etoposide sensitive MCF7 breast cancer cell lines. PLoS One. 2012;7(9).

HOW TO CITE THIS ARTICLE: Pandya H, Patel CN, Bhavsar M, Pandya PN, Patel SK, Rawal RM. Analyzing the role of phytochemicals in targeting drug transporter protein ABCC6 using molecular docking and molecular dynamics simulations. Int. J. Pharm. Sci. Drug Res. 2020;12(3):275-281. DOI: $10.25004 /$ IJPSDR.2020.120310 